\title{
Preparation, Characterizations and Conductivity of Composite Polymer Electrolytes Based on PEO-LiClO 4 and Nano ZnO Filler
}

\author{
Abdelhameed Ahmed EIBellihi, Wafaa Abdallah Bayoumy, Emad Mohamed Masoud," and Mahmoud Ahmed Mousa \\ Department of Chemistry, Faculty of Science, Benha University, Benha, Egypt. *E-mail: emad_masoud1981@yahoo.com \\ Received April 27, 2012, Accepted June 8, 2012
}

\begin{abstract}
Nano $\mathrm{ZnO}$ with an average size of $8 \mathrm{~nm}$ was prepared by thermal decomposition of zinc oxalate at $450{ }^{\circ} \mathrm{C}$. A series of based composite polymer electrolyte $\mathrm{PEO}-\mathrm{LiClO}_{4}$ and nano $\mathrm{ZnO}$ as a filler have been synthesized using solution cast technique, with varying the filler ratio systematically. XRD, DSC and FTIR studies have been conducted to investigate the structure and interaction of different groups in the composite polymer electrolyte. Effect of nano $\mathrm{ZnO}$ ceramic filler concentration on the structure of composites and their electrical properties (DC-conductivity, AC-conductivity, dielectric constant, dielectric loss and impedance) at different frequencies and temperatures was studied. Melting temperature $\left(\mathrm{T}_{\mathrm{m}}\right)$ of PEO decreased with the addition of both $\mathrm{LiClO}_{4}$ salt and nano $\mathrm{ZnO}$ filler due to increasing the amorphous state of polymer. All composite samples showed an ionic conductivity. The maximum room temperature ionic conductivity is found for $(\mathrm{ZnO})_{0.5}(\mathrm{PEO})_{12}\left(\mathrm{LiClO}_{4}\right)$ composite sample. All the results are correlated and discussed.
\end{abstract}

Key Words : PEO-based polymer electrolyte, Ionic conductivity, Nano composites

\section{Introduction}

There has been increasing interest in the development of solid polymer electrolytes, due to their applications in solidstate electrochemical device, and particularly in solid state rechargeable lithium batteries. ${ }^{1}$ Solid polymer electrolytes for lithium batteries have many advantages over their counterpart liquid electrolytes, such as processing flexibility, but their conductivity at room temperature is usually too low to be applicable. Improvement the ionic conductivity of these electrolytes can be achieved by fillers. At least there are two types of fillers to improve the ionic conductivity of PEObased polymer electrolytes. One is small organic molecules, such as ethylene carbonate and propylene carbonate, ${ }^{2}$ which can enhance the polymer electrolyte conductivity to a moderate value. But this makes the systems appearing as a gel or like a liquid, which loses the advantages of solid polymer electrolytes to some extent. The other is dry inorganic compounds as ceramic powders which can enhance not only the conductivity but also the stability of the polymer in the meantime. ${ }^{3}$ Among various choices of lithium salts as the inorganic conducting ion components in polymeric electrolytes, $\mathrm{LiClO}_{4}$ is the most attractive because it exhibits a great charge delocalization favorable to ionic dissociation in a solvating polymer such as polyethylene oxide. This article is a part of our program to prepare polymer composite electrolytes and study the effect of nano materials on their physical properties. In this article, nano $\mathrm{ZnO}$ with an average particle size of $8 \mathrm{~nm}$ was synthesized using thermal decomposition method and then used to prepare polymer nano composite electrolytes $(\mathrm{ZnO})_{\mathrm{x}}(\mathrm{PEO})_{12.5-\mathrm{x}}\left(\mathrm{LiClO}_{4}\right),(\mathrm{x}=0.0-1.75)$. The effect of $\mathrm{ZnO}$ concentration and temperature on the electrical properties (dielectric properties, impedance, dc- and ac- conductivity) was one of our targets.

\section{Experimental}

Materials. Pure reagent materials of zinc acetate dehydrate [LOBA Chemie PVT. LTD.], oxalic acid [Bio-Chem.], polyethylene oxide $\left[\mathrm{M} . w \mathrm{t}=8 \times 10^{6}\right.$, Sigma-Aldrich $]$ and $\mathrm{LiClO}_{4}$ [Sigma-Aldrich] were used as starting materials to prepare nano filler and polymer nano composite electrolyte.

Preparation of Nano ZnO Filler. $300 \mathrm{~mL}$ of $0.15 \mathrm{M}$ oxalic acid solution was added slowly (drop by drop) to 300 $\mathrm{mL}$ of $0.1 \mathrm{M}$ zinc acetate solution under stirring for $18 \mathrm{hrs}$. A white precipitate of zinc-oxalate was obtained, which was filtered and washed with acetone several times to remove impurities. The precursor was then dried at $120{ }^{\circ} \mathrm{C}$ for 30 minutes and finally heated for 30 minutes at $450{ }^{\circ} \mathrm{C}$ to get nano $\mathrm{ZnO}$.

Preparation of Polymer Nano Composite Electrolytes. The composite samples were synthesized by the conventional solution cast technique. PEO and $\mathrm{LiClO}_{4}$ were dissolved in acetonitrile and magnetically stirred to get a homogeneous solution. An appropriate weight of nano zinc oxide was then added to the solution and stirred for $6 \mathrm{hrs}$ getting a white viscous solution with high homogeneity. After that, the viscous solution was poured on peter dish and left to dry at room temperature for two days to allow the solvent to be evaporated slowly. All the films obtained with different concentrations of filler were then dried under vacuum for 10 hrs and kept in a desiccator.

Characterization of Samples. X-ray diffraction was performed on the investigated samples using a Philips X-ray diffractometer (Model PW 1710) with $\mathrm{CuK \alpha}$ radiation $(\lambda=1.54 \AA)$ in the range of $2 \theta=4-60^{\circ}$. Thermal analysis was performed on the samples investigated in air atmosphere and at a temperature range of 298-353 K using differential scanning calorimetry technique (DSC) by Shimadzu DSC- 
$60 \mathrm{H}$. FT-IR spectra of the samples were recorded in the range of $400-3000 \mathrm{~cm}^{-1}$ using $\mathrm{KBr}$ pellet technique on IRBrucker, Vector 22, Germany.

\section{Results and Discussion}

XRD pattern of $\mathrm{ZnO}$, Figure 1, shows typical peaks characterized for $\mathrm{ZnO}$ with high crystallinity hexagonal wurtzite-structured $(\mathrm{p} 63 \mathrm{mc})$ as indexed in the standard data (JCPDS card No. 36-1451, $\mathrm{a}=3.249 \AA$ and $\mathrm{c}=5.206 \AA$ ). ${ }^{4}$ XRD line broadening was used to estimate the grain size of the powders according to Scherrer formula ${ }^{5}$ :

$$
\mathrm{D}=0.9 \lambda / \beta \cos \theta
$$

Where $\mathrm{D}$ is the average diameter of the grains, $\lambda$ is the wavelength of $\mathrm{X}$-ray, $\theta$ is the Bragg angle and $\beta$ is the full width half maximum in radians calculated using Gaussian fitting. The results showed an average crystalline size of about $8 \mathrm{~nm}$. XRD of pure PEO and composites of $(\mathrm{ZnO})_{\mathrm{x}}(\mathrm{PEO})_{12.5-\mathrm{x}}$ $\left(\mathrm{LiClO}_{4}\right),(\mathrm{x}=0,0.5,0.75,1.25$, and 1.75 mole $)$ are also shown in Figure 1. The XRD of PEO polymer showed crystallinity behavior due to the appearance of characteristic diffraction peaks in the range of $2 \theta=19-23^{\circ}{ }^{6}$. Whereas, the XRD of the composites containing $\mathrm{LiClO}_{4}$ and nano $\mathrm{ZnO}$ showed a remarkable reduction in the intensity of XRD peaks of pure PEO, specially for the sample containing 0.5 mole $\mathrm{ZnO}$, which showed a complete amorphous nature. This can be attributed to a destruction effect of the filler on the ordered arrangement of the polymer side chains, and hence an enhancement in the amorphous phase.

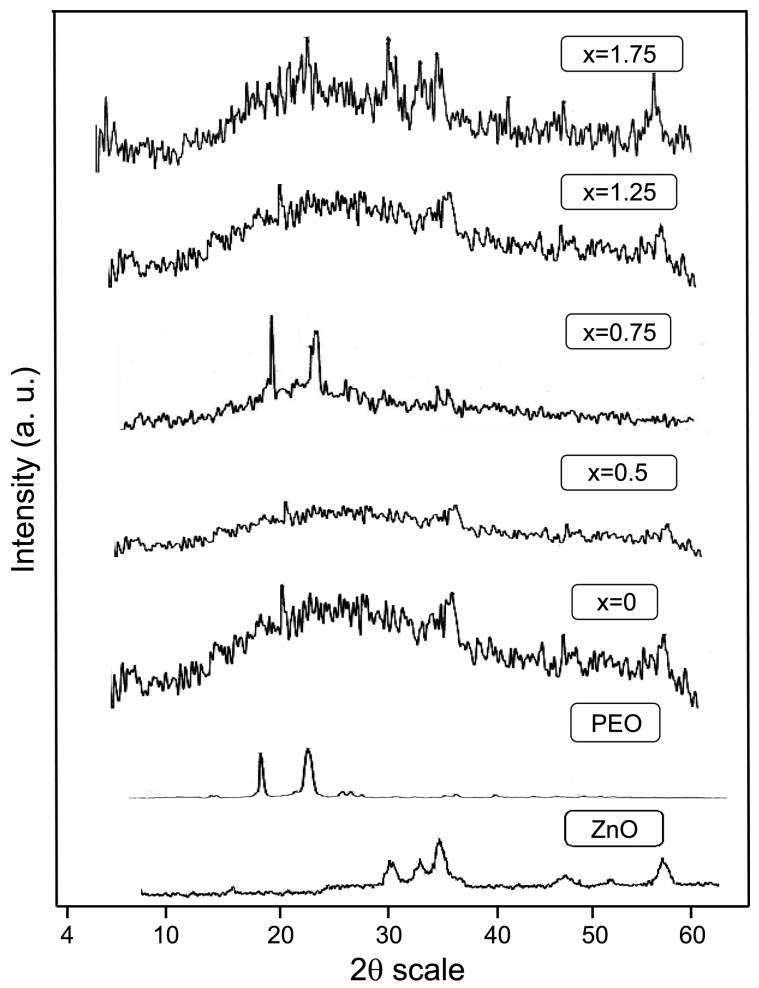

Figure 1. XRD Patterns of $\mathrm{ZnO}$, pure $\mathrm{PEO}$ and $(\mathrm{ZnO})_{\mathrm{x}}(\mathrm{PEO})_{12.5-\mathrm{x}}$ $\left(\mathrm{LiClO}_{4}\right),(\mathrm{x}=0,0.5,0.75,1.25,1.75$ mole $)$.

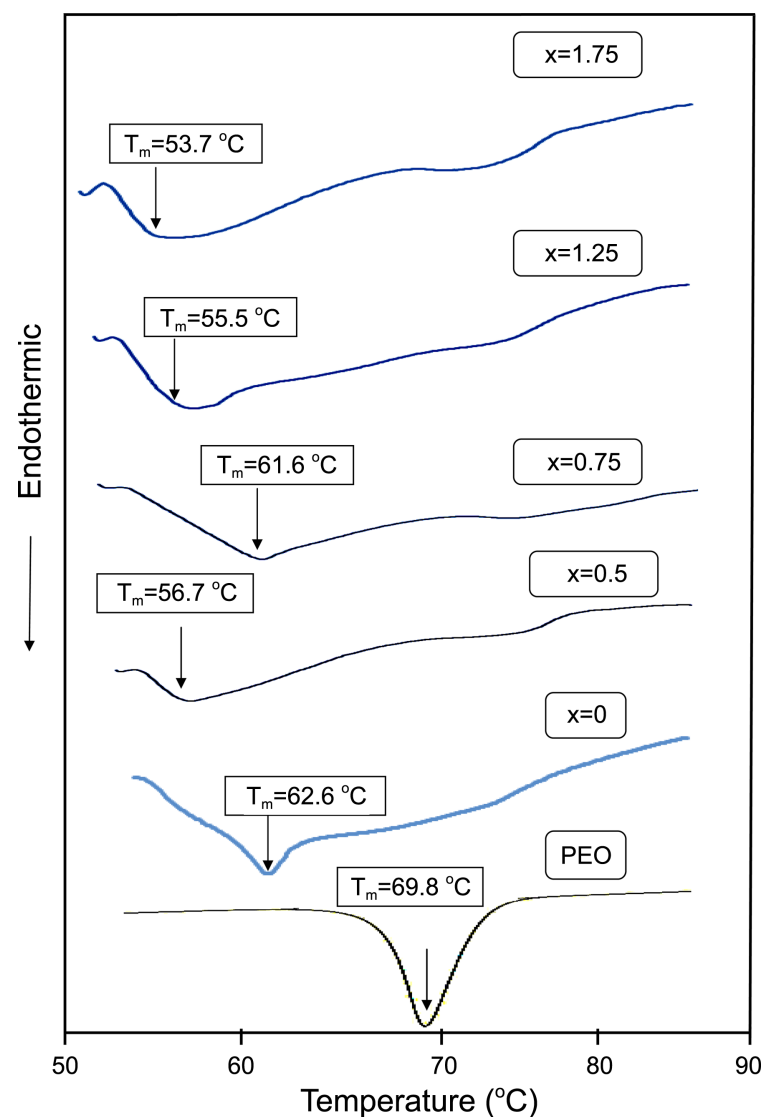

Figure 2. DSC curves of pure $\mathrm{PEO}$ and $(\mathrm{ZnO})_{\mathrm{x}}(\mathrm{PEO})_{12.5-\mathrm{x}}$ $\left(\mathrm{LiClO}_{4}\right),(\mathrm{x}=0,0.5,0.75,1.25,1.75$ mole $)$.

DSC thermograms of pure PEO and $(\mathrm{ZnO})_{\mathrm{x}}(\mathrm{PEO})_{12.5-\mathrm{x}}$ $\left(\mathrm{LiClO}_{4}\right),(\mathrm{x}=0,0.5,0.75,1.25$, and 1.75 mole $)$ were displayed in Figure 2. The relative percentage of crystallinity $\left(\mathrm{X}_{\mathrm{c}}\right)$ has been calculated by taking into account pure $100 \%$ crystallinity for $\mathrm{PEO}^{6}$ and using the equation

$$
\mathrm{X}_{\mathrm{c}}=\Delta \mathrm{H}_{\mathrm{c}} / \Delta \mathrm{H}_{\mathrm{p}}
$$

Where, $\Delta \mathrm{H}_{\mathrm{p}}$ equals to $203 \mathrm{~J} / \mathrm{g}$ which is the heat enthalpy of $100 \%$ crystalline PEO melting, ${ }^{6}$ and $\Delta \mathrm{H}_{\mathrm{c}}$ is the heat enthalpy of composites melting. The calculated relative crystallinity $\left(\mathrm{X}_{\mathrm{c}}\right)$ and the data obtained from DSC thermograms are summarized in Table 1. From which it can be seen that the melting temperature $\left(T_{m}\right)$ of crystalline PEO phase decreases with increasing the amount of $\mathrm{ZnO}$. This refers to increase the flexibility with increasing the amount of $\mathrm{ZnO}$ in the PEO matrix.

The FT-IR spectra of $\mathrm{ZnO}, \mathrm{PEO}, \mathrm{LiClO}_{4}$ and $(\mathrm{ZnO})_{\mathrm{x}}$ $(\mathrm{PEO})_{12.5-\mathrm{x}}\left(\mathrm{LiClO}_{4}\right),(\mathrm{x}=0,0.5,0.75,1.25$, and 1.75 mole $)$ are shown in Figure 3. The spectra of the composite systems display some spectral features that are similar to those of pure PEO. However, the incorporation of both $\mathrm{LiClO}_{4}$ and nano $\mathrm{ZnO}$ particles causes shifts of some PEO bands. At frequency range $\left(1050-1160 \mathrm{~cm}^{-1}\right)$, significant changes were observed in the width and intensity of the vibrational bands of PEO due to the addition of $\mathrm{LiClO}_{4}$ salt and nano $\mathrm{ZnO}$ filler. These changes were attributed to the effect of both $\mathrm{LiClO}_{4}$ and nano $\mathrm{ZnO}$ on $\mathrm{C}-\mathrm{O}-\mathrm{C}$ symmetric vibrational 
Table 1. Melting temperatures $\left(\mathrm{T}_{\mathrm{m}}\right)$, melting enthalpy $\left(\Delta \mathrm{H}_{\mathrm{m}}\right)$ and crystallinity $\left(\mathrm{X}_{\mathrm{c}}\right)$ for $(\mathrm{ZnO})_{\mathrm{x}}(\mathrm{PEO})_{12.5-\mathrm{x}}\left(\mathrm{LiClO}_{4}\right)$

\begin{tabular}{cccc}
\hline$(\mathrm{X}),($ mole $)$ & $\mathrm{T}_{\mathrm{m}}\left({ }^{\circ} \mathrm{C}\right)$ & $\Delta \mathrm{H}_{\mathrm{m}}(\mathrm{J} / \mathrm{g})$ & $\mathrm{X}_{\mathrm{c}}(\%)$ \\
\hline pure PEO & 69.8 & 139.1 & 68.5 \\
0 & 62.6 & 52.3 & 25.8 \\
0.5 & 56.7 & 71.3 & 35.1 \\
0.75 & 61.6 & 160.6 & 79.1 \\
1.25 & 55.5 & 94.8 & 46.7 \\
1.75 & 53.7 & 197.1 & 97.1 \\
\hline
\end{tabular}

modes. The peak around $2900 \mathrm{~cm}^{-1}$ in pure PEO is believed from the vibrations of $\mathrm{C}-\mathrm{H}$ bond. After the addition of $\mathrm{LiClO}_{4}$ and $\mathrm{ZnO}$, width and intensity of peak decreases with increasing $\mathrm{ZnO}$ content and some shifts also were observed. Also, the rest of the bands at $2900 \mathrm{~cm}^{-1}$ is found to be similar to those of PEO. This confirms that the gauche CO-CO conformation of pure PEO remains unaffected on interactions. Similarly, the vibrational bands of pure PEO seen in the range $1242-1280 \mathrm{~cm}^{-1}$ which are assigned to $\mathrm{CH}_{2}$ wagging modes. Metal oxygen stretching frequency of $525 \mathrm{~cm}^{-1}$ in pure $\mathrm{ZnO}$ is shifted to $587 \mathrm{~cm}^{-1}$ in the composite indicating the van der-Waals interaction between $\mathrm{ZnO}$ and PEO polymer. Moreover, the shifts occurring in the vibrational band of C-O-C at $800-1000 \mathrm{~cm}^{-1}$ refer to the interaction of $\mathrm{Zn}^{2+}$ metal ion with the ether oxygen. ${ }^{7,8}$ Generally, the changes

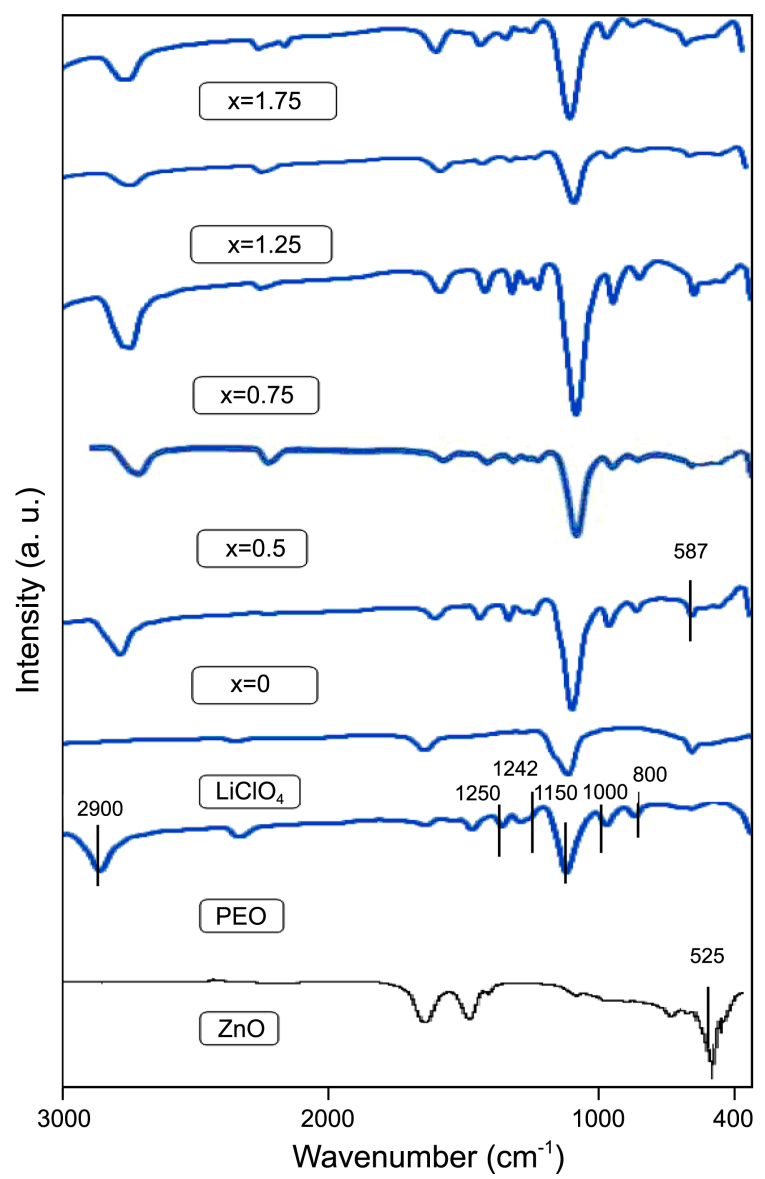

Figure 3. FT-IR Patterns of $\mathrm{ZnO}, \mathrm{PEO}, \mathrm{LiClO}_{4}$ and $(\mathrm{ZnO})_{\mathrm{x}}$ $(\mathrm{PEO})_{12.5-\mathrm{x}}\left(\mathrm{LiClO}_{4}\right),(\mathrm{x}=0,0.5,0.75,1.25,1.75$ mole $)$. occurring in FT-IR spectra confirm the complexation process in the polymer nano composite electrolytes samples with each of $\mathrm{Zn}^{2+}$ and $\mathrm{Li}^{+}$ions. This interaction may be associated with the interaction of $\mathrm{Zn}^{2+}$ ion and oxygen atom in PEO macromolecule. This interaction may weaken the bond strengths of C-O-C in PEO macromolecule.

DC-Electrical Conductivity. The temperature dependence of electrical conductivity $(\mathrm{DC})$ of $(\mathrm{ZnO})_{\mathrm{x}}(\mathrm{PEO})_{12.5-\mathrm{x}}$ $\left(\mathrm{LiClO}_{4}\right),(\mathrm{x}=0,0.5,0.75,1.25$, and 1.75 mole $)$ is investigated in a temperature range of $293-323 \mathrm{~K}$ and illustrated in Figure 4 . The overall feature of the plots is almost similar for all investigated composites. The conductivity data are summarized and given in Table 2. Generally, it can be seen that the addition of nano $\mathrm{ZnO}$ in the $\mathrm{PEO}-\mathrm{LiClO}_{4}$ matrix causes a high enhancement in the conductivity of the composite electrolyte. Electrical conductivity reached a value higher 100 times more than that of the polymer electrolyte system PEO-LiClO 4 , Table 2. The increase in conductivity may be attributed to an increase occurring in the flexibility of the composite by introducing $\mathrm{ZnO}$ into $\mathrm{PEO}$ matrix, due to the high interface area between the matrix and the dispersed nano $\mathrm{ZnO}$ particles. ${ }^{9-11}$ Moreover, the increase in amorphous phase within the PEO-matrix due to the addition of nano $\mathrm{ZnO}$ causes an enhancement in the segmental motion of the polymer chains and hence increases the conductivity.

The small particle of $\mathrm{ZnO}$ in our samples $(8 \mathrm{~nm})$ is more efficient than that of $60 \mathrm{~nm}$ reported before by L. Fan et al. ${ }^{9}$ for the same system of PEO-LiClO 4 , where it showed ionic conductivity value equals $5 \times 10^{-6} \mathrm{ohm}^{-1} \cdot \mathrm{cm}^{-1}$ at room temperature. This indicates that smaller particle size plays an important role in enhancing the conductivity of the polymer electrolyte through Lewis acid-base interactions.

Figure 5 shows a non linear increase in conductivity of the composite with increasing the concentration of nano $\mathrm{ZnO}$

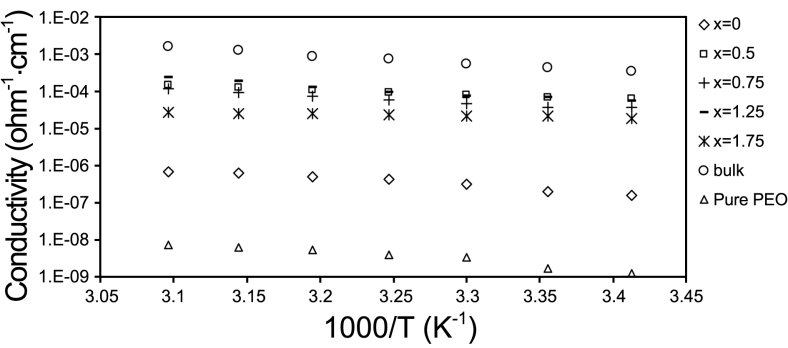

Figure 4. Temperature dependence of DC-conductivity for pure PEO and composite samples with different $x$ values and bulk conductivity at $x=0.5$ mole.

Table 2. DC and bulk conductivity $\left(\sigma_{\mathrm{dc}}, \sigma_{\mathrm{b}}\right)$ data for $(\mathrm{ZnO})_{\mathrm{x}}$ $(\mathrm{PEO})_{12.5-\mathrm{x}}\left(\mathrm{LiClO}_{4}\right)$ at room temperature $(293 \mathrm{~K})$

\begin{tabular}{ccccc}
\hline$(\mathrm{X}),(\mathrm{mole})$ & $\left(\mathrm{E}_{\mathrm{a}}\right)(\mathrm{eV})$ & $\sigma_{\mathrm{dc}}\left(\mathrm{ohm}^{-1} \cdot \mathrm{cm}^{-1}\right)$ & $\sigma_{\mathrm{b}}\left(\mathrm{ohm}^{-1} \cdot \mathrm{cm}^{-1}\right)$ & $\left(\mathrm{E}_{\mathrm{a}}\right)(\mathrm{eV})$ \\
\hline Pure PEO & 0.40 & $1.25 \times 10^{-9}$ & $7.00 \times 10^{-7}$ & 0.33 \\
0 & 0.46 & $1.55 \times 10^{-7}$ & $1.60 \times 10^{-4}$ & 0.55 \\
0.5 & 0.24 & $6.33 \times 10^{-5}$ & $3.42 \times 10^{-4}$ & 0.43 \\
0.75 & 0.36 & $3.72 \times 10^{-5}$ & $1.10 \times 10^{-4}$ & 0.60 \\
1.25 & 0.41 & $5.43 \times 10^{-5}$ & $2.00 \times 10^{-4}$ & 0.53 \\
1.75 & 0.55 & $1.95 \times 10^{-5}$ & $5.51 \times 10^{-5}$ & 0.62 \\
\hline
\end{tabular}




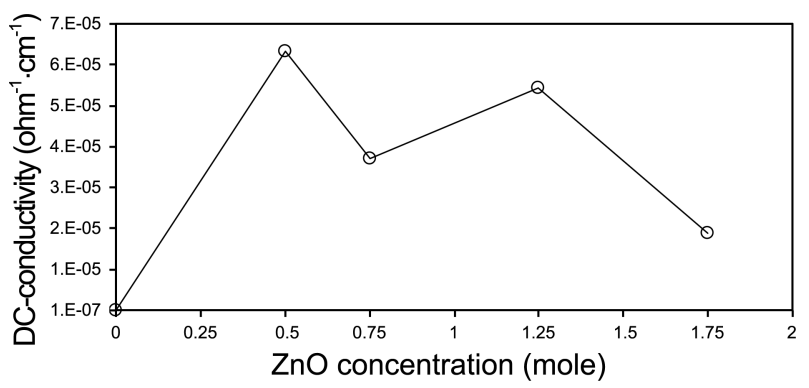

Figure 5. $\mathrm{ZnO}$ concentration dependence of dc-conductivity $\left(\sigma_{\mathrm{dc}}\right)$ for $(\mathrm{ZnO})_{\mathrm{x}}(\mathrm{PEO})_{12.5-\mathrm{x}}\left(\mathrm{LiClO}_{4}\right),(\mathrm{x}=0,0.5,0.75,1.25,1.75$ mole $)$ at room temperature $(293 \mathrm{~K})$.

filler. The two maxima appearing in Figure 5 have been also reported by few workers for other systems of ion conducting gel polymer electrolyte composite ${ }^{12}$ and also for solvent free composite polymer electrolytes. ${ }^{13,14}$ The first conductivity maximum is possibly due to the dissociation of ion aggregates salt into the free ions with the addition of nano sized $\mathrm{ZnO}$ particles. Whereas the second conductivity maximum is related to the composite effect and explained on the basis of formation of a conducting interfacial space-charge double layer between the nano sized $\mathrm{ZnO}$ particles and polymer electrolytes. ${ }^{10,15}$ The decrease in conductivity after the second conductivity maximum (Figure 5) is generally related to the blocking effect of filler particles, which hinders the motion of mobile ions. ${ }^{16}$ The conductivity results, Table 2 , showed a highest conductivity value for the sample containing 0.5 mole $\mathrm{ZnO}$ because this sample containing the highest amorphous structure (see XRD) which facilitate the transport of ionic charge carriers, as will be seen later.

The increase observed in conductivity with temperature, Figure 4, can be attributed to the decrease in the viscosity and hence the flexibility chain of the sample. ${ }^{17}$ The conductivity data present in Table 2 show an activation energy value $(0.46 \mathrm{eV})$ for the sample free from nano $\mathrm{ZnO}$ filler more than that of the samples containing $\mathrm{ZnO}$ filler $(0.24$ $\mathrm{eV})$. This low value of activation energy in our sample can be attributed to the amorphous nature of the sample that will facilitate the $\mathrm{Li}^{+}$ion motion in the polymer network, ${ }^{18}$ as shown in the results of impedance. The electrical devices that work over a wide temperature range should have uniform conductivity, thus, materials with low activation energy is a good electrical system. ${ }^{19}$ Therefore, the composite system containing 0.5 mole nano $\mathrm{ZnO}$ was chosen to be more studied using ac-conductivity, dielectric behavior, and impedance character.

Impedance Spectroscopy Analysis. Impedance plots ( $Z^{\prime}$ $\left.v s . Z^{\prime \prime}\right)$ in the complex plan for $(\mathrm{ZnO})_{0.5}(\mathrm{PEO})_{12}\left(\mathrm{LiClO}_{4}\right)$ at different temperatures showed similar behavior. A typical plot is shown in Figure 6, which demonstrates a depressed semicircular portion followed by a spike. This spike refers to ionic conductivity and is characteristic of a blocking double layer capacitance whose magnitude can be estimated from any position on the spike using the equation. $Z^{\prime \prime}=1 / 2 \pi \mathrm{fC}_{\mathrm{di}}$, where $f$ is the frequency and $C_{d i}$ is the capacitance at the frequency $\mathrm{f}$. The ionic conductivity of the solid polymer

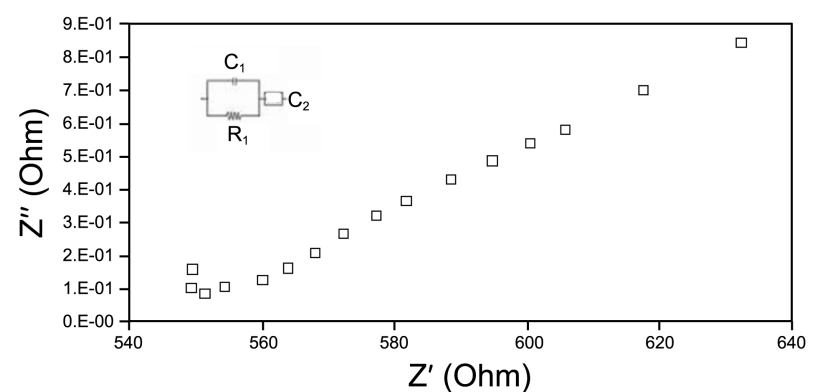

Figure 6. Plot of $\mathrm{Z}^{\prime \prime}$ versus $\mathrm{Z}^{\prime}$ for $(\mathrm{ZnO})_{0.5}(\mathrm{PEO})_{12}\left(\mathrm{LiClO}_{4}\right)$, at room temperature $(293 \mathrm{~K})$.

nano composite electrolyte $(\mathrm{ZnO})_{0.5}(\mathrm{PEO})_{12}\left(\mathrm{LiClO}_{4}\right)$ was derived from the ac impedance analysis. The high depression of semicircular portion at high frequencies, in complex impedance, is a result of the increase in ionic conductivity with increasing the frequency. ${ }^{9}$ The equivalent circuit of the polymer nano composite electrolyte system is determined from the complex impedance spectrum and given in Figure 6 , where, $R_{1}$ is the bulk resistance of the electrolyte, $C_{1}$ is the bulk capacity of the electrolyte and $\mathrm{C}_{2}$ is a capacity of bulk electrode-electrolyte interface. A bulk ionic conductivity value of $3.42 \times 10^{-4} \mathrm{ohm}^{-1} \mathrm{~cm}^{-1}$ at room temperature was calculated using the equation $\sigma_{b}=L / R_{b} A$, where $L$ is the thickness of the polymer nano composite electrolyte film and $\mathrm{A}$ is the surface area of it. The resistance of the electrolyte $\left(\mathrm{R}_{\mathrm{b}}\right)$ was determined from the intercept of the impedance spectrum on the $Z^{\prime}$ real axis. The temperature dependence of the bulk conductivity showed a linear behavior, Figure 4, as that reported by dc-conductivity. The bulk conductivity data are also reported in Table 2 . The difference between dc and impedance data is attributed to the grain boundaries present between the particles.

AC-Conductivity. In order to give information on the type of polarization present in $(\mathrm{ZnO})_{0.5}(\mathrm{PEO})_{12}\left(\mathrm{LiClO}_{4}\right)$ sample, the ac-electrical conductivity $\left(\sigma_{\mathrm{ac}}\right)$ at temperatures between $293-323 \mathrm{~K}$ and at a frequency range of $10^{2}-10^{5} \mathrm{~Hz}$ was studied in Figure 7. It can be seen that, the conductivity increases with each of the frequency and temperature. The frequency dependence of conductivity is attributed to the change occurring in mobility of charge carriers. The increase in $\sigma_{\mathrm{ac}}$ with temperature can be explained on the basis that raising the temperature causes more structure relaxation and

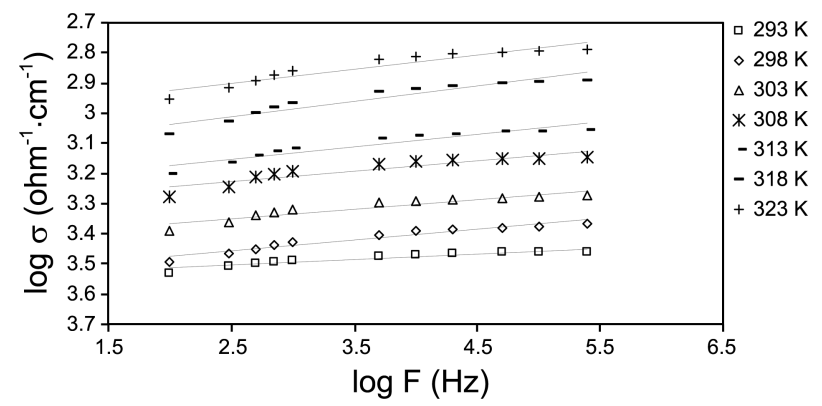

Figure 7. Variation of electrical conductivity $(\mathrm{AC})$ with frequency at different temperatures for $(\mathrm{ZnO})_{0.5}(\mathrm{PEO})_{12}\left(\mathrm{LiClO}_{4}\right)$. 
(a)

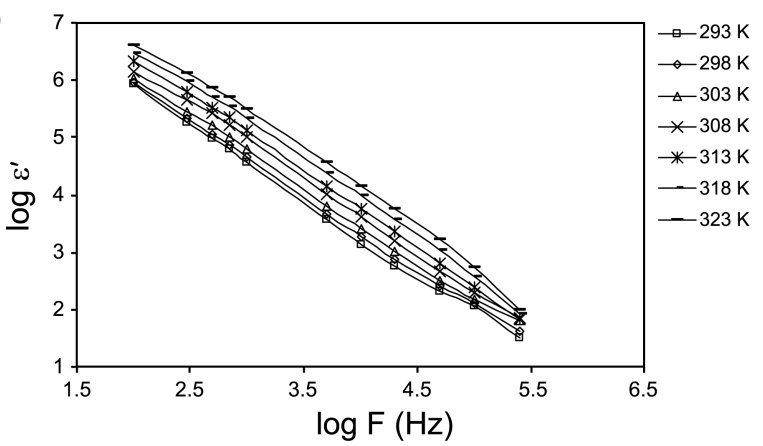

(b)

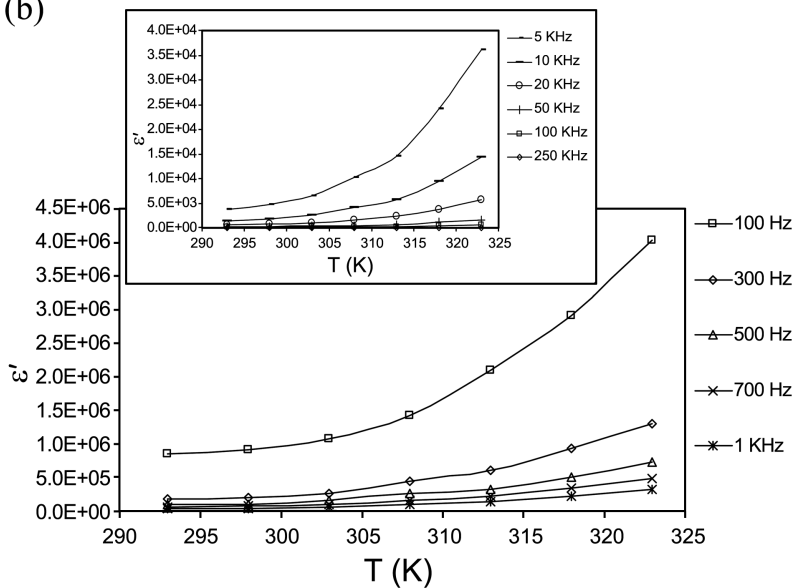

Figure 8. (a) Variation of dielectric constant with frequency at different temperatures for $(\mathrm{ZnO})_{0.5}(\mathrm{PEO})_{12}\left(\mathrm{LiClO}_{4}\right)$. (b) Variation of dielectric constant with temperature at different frequencies for $(\mathrm{ZnO})_{0.5}(\mathrm{PEO})_{12}\left(\mathrm{LiClO}_{4}\right)$.

releasing more of $\mathrm{Li}^{+}$ions attached oxygen of $\mathrm{PEO}$ to become more mobilized. This may be also due to increasing the drift mobility and hopping frequency of charge carriers.

Dielectric Permittivity and Loss Studies. The frequency dependence of dielectric constant $\varepsilon^{\prime}$ at different temperatures for $(\mathrm{ZnO})_{0.5}(\mathrm{PEO})_{12}\left(\mathrm{LiClO}_{4}\right)$ sample is shown in Figure 8(a). It can be seen that $\varepsilon^{\prime}$ decreases as frequency increases. This decrease is relatively sharp at lower frequencies and slower at higher ones. The decrease in dielectric permittivity with increasing frequency can be associated to the inability of dipoles to rotate rapidly leading to a lag between frequency of oscillating dipole and that of applied field. ${ }^{20}$ The dielectric (permittivity obtained in our system $\varepsilon^{\prime}=8.58 \times$ $10^{5}$, at room temperature) is higher than that for other compositions of polymer electrolytes. $\left(\varepsilon^{\prime}\right.$ lie in the range of $9.8 \times 10^{-3} \sim 1.52 \times 10^{5}$, at room temperature). Such high dielectric constant values in our sample can be attributed to high ionic conductivity on account of the presence of nano particles of zinc oxide and its good distribution within the matrix of poly ethylene oxide and also due to the good interactions between the lewis acidic sites on the surface of those particles and the ions of the lithium perchlorate. ${ }^{21}$ When the temperature is raised, dielectric constant also enhances due to the facilitation in orientation of dipoles within the matrix of PEO.

The temperature dependence of dielectric constant at

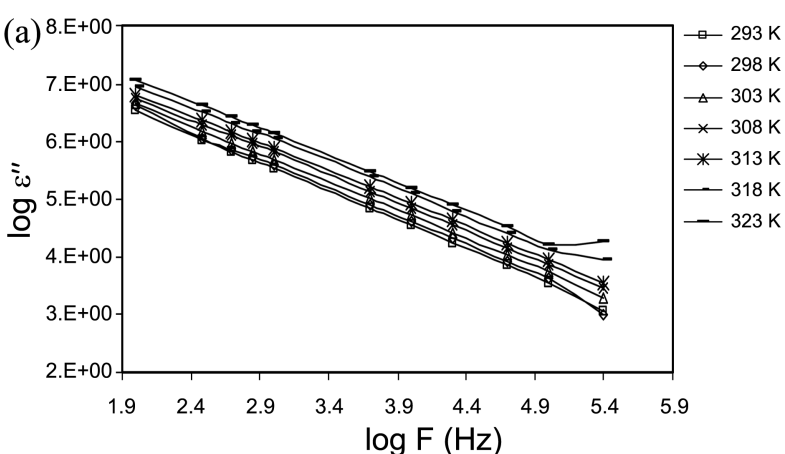

(b)

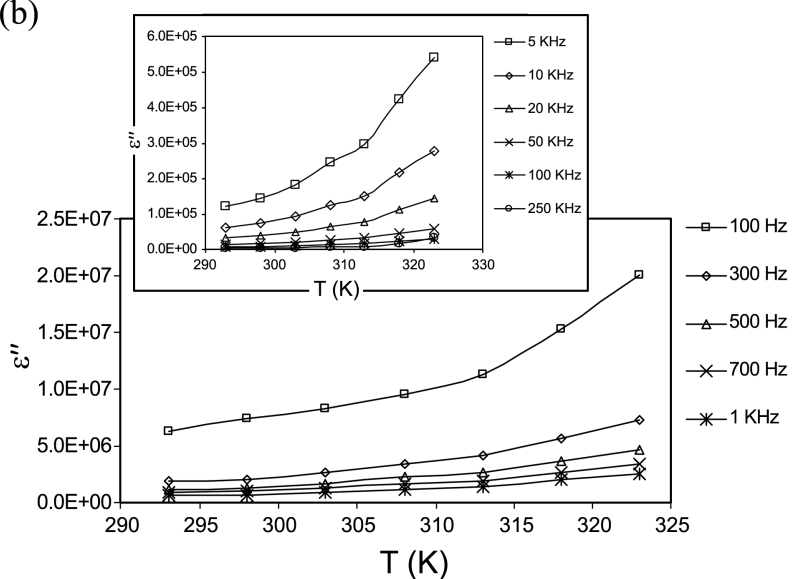

Figure 9. (a) Variation of dielectric loss with frequency at different temperatures for $(\mathrm{ZnO})_{0.5}(\mathrm{PEO})_{12}\left(\mathrm{LiClO}_{4}\right)$. (b) Variation of dielectric loss with temperature at different frequencies for $(\mathrm{ZnO})_{0.5}(\mathrm{PEO})_{12}$ $\left(\mathrm{LiClO}_{4}\right)$.

different frequencies is shown in Figure 8(b). The variation of dielectric constant with temperature can be divided into two ranges, in the low temperatures range (from 293 to 303 $\mathrm{K})$, the change in the dielectric constant is weakly dependent on the temperature but in the higher temperatures range (from 303 to $323 \mathrm{~K}$ ), the dielectric constant is strongly dependent on the temperature. The increase of dielectric constant with temperature is generally attributed to two mechanisms. The first is to the decrease of viscosity of the polymer nano composite electrolyte ${ }^{22}$ and the second is to the dissolving of any small concentration of crystalline and semi-crystalline phases into the amorphous phase. ${ }^{20}$ This is in turn influences the polymer dynamics and thus the dielectric behavior. The present of the two ranges in Figure 8(b) may be attributed to the effect of the two mechanisms. Whereas, at lower temperature range the viscosity is high and crystalline phases are present, thus the dielectric behavior is weakly dependent on the temperature, while at higher temperatures the opposite trend is predominate.

Figure 9(a), (b) shows the variation of dielectric loss $\varepsilon^{\prime \prime}$ with frequency and temperature for $(\mathrm{ZnO})_{0.5}(\mathrm{PEO})_{12}\left(\mathrm{LiClO}_{4}\right)$ sample. The behaviors observed are similar to that found for dielectric constant. Where, the dielectric loss decreased with increasing the frequency due to high periodic reversal of the field at the interface; the contribution of charge carriers (ions) towards the dielectric loss decreases with increasing 
frequency. This decrease can be also attributed to the reduction of the diffusion of the ions in the polymer matrix with increasing the frequency. Also, the increase in dielectric loss with increasing temperature can be attributed to the relaxation of the dipoles in co-operation with the resulting drop in the relaxation time.

\section{Conclusions}

Nano $\mathrm{ZnO}$ filler with an average particle size of $8 \mathrm{~nm}$ was prepared using a thermal decomposition of zinc oxalate. A series of polymer nano composite electrolytes $(\mathrm{ZnO})_{\mathrm{x}}$ $(\mathrm{PEO})_{12.5-\mathrm{x}}\left(\mathrm{LiClO}_{4}\right),(\mathrm{x}=0.0-1.75)$ has been prepared. Shifts, broadening and reduction in the intensity of the FT-IR-bands confirm the dissolution of the metal salt in the polymer matrix. The DSC analysis revealed to a change in the crystallinity and melting points of the composite samples with different filler concentrations. All composite samples showed an ionic conductivity, in which the addition of nano $\mathrm{ZnO}$ particles enhances the ionic conductivity of the based polymer by hundred times at room temperature. The maximum room conductivity value of $6.33 \times 10^{-5} \mathrm{ohm}^{-1} \cdot \mathrm{cm}^{-1}$ is found for the composite polymer electrolyte containing 0.5 mole $\mathrm{ZnO}$. The electrical properties of this sample showed dielectric permittivity and loss values of $8.58 \times 10^{5}$ and 6.30 $\times 10^{6}$ respectively at room temperature. These high values of dc-conductivity, dielectric permittivity and dielectric loss at room temperature lead to make the sample as a promising material for lithium battery as an application in the solid state electrochemical devices.

\section{References}

1. Tarascon, J. M.; Armand, M. Nature 2001, 414, 359.
2. Bishop, A. G.; Macfarlane, D. R.; McNaughton, D.; Forsyth, M. J. Phys. Chem. 1996, 100, 2237.

3. Quartarone, E.; Mustarelli, P.; Magistris, A. Solid State Ionics 1998, 110,1 .

4. Liu, J.; Huang, X.; Duan, J.; Ai, H.; Tu, P. Mat. Lett. 2005, 59, 3710.

5. Klug, H. P.; Alexander, L. E. X-ray Diffraction Procedures; Wiley: New York, 1970.

6. Wunderlich, B. Macromolecular Physics; Academic Press: New York, 1980, 3, 67.

7. Papke, B. L.; Ratner, M. A.; Shriver, D. F. J. Electrochem. Soc. 1982, 129, 1434.

8. Wen, S. J.; Richrdson, T. J.; Ghantous, D. I.; Striebel, K. A.; Ross, P. N.; Cairns, E. J. J. Electroanal. Chem. 1996, 408, 113.

9. Fan, L.; Dang, Z.; Wei, G.; Wen, N. C.; Li, M. Mater. Sci. and Eng. B 2003, 99, 340.

10. Maier, J. Solid State Ionics 1994, 70-71, 43. Prog. Solid State Chem. 1995, 23, 171.

11. Wieczorek, W.; Raducha, D.; Zalewska, A. J. Phys. Chem. B 1998, 102, 8725 .

12. Sharma, J. P.; Sekhon, S. S. Solid State Ionics 2007, 178, 439.

13. Hashmi, S. A.; Upadhayaya, H. M.; Thakur, A. K. Solid State Ionics: Materials and Devices; Chodari, B. V. R., Wang, W., Eds.; World Scientific: Singapore, 2000; 461.

14. Pandey, G. P.; Hashmi, S. A.; Agrawal, R. C. Solid State Ionics 2008, 179, 543.

15. Kumar, B. J. Power Sources 2004, 135, 215.

16. Kumar, B.; Nellutla, S.; Thokchom, J. S.; Chen, C. J. Power Sources 2006, 160, 1329.

17. Tsunemi, K.; Ohno, H.; Tsuchida, E. Electrochem. Acta 1983, 28(6), 833.

18. Baskaran, R.; Selvasekarapandian, S.; Kuwata, N.; Kawamura, J.; Hattori, T. J. Phys. and Chem. of Sol. 2007, 68, 407.

19. Cowie, J. M. G.; Spence, G. H. Solid State Ionics 1998, 109, 139.

20. Awadhia, A.; Patel, S. K.; Agrawal, S. L. Prog. in Crystal Growth and Character. of Mater. 2006, 52, 61.

21. Finch, C. A. Polyvinyl Alcohol: Properties and Applications; John Wiley; Sons Ltd., London, 1973.

22. Singh, K. P.; Gupta, P. N.; Singh, R. P. J. Polym. Mater. 1992, 9, 131. 